\title{
VIABILIDADE DE PRODUÇÃO DA VIDEIRA ‘SYRAH', EM CICLO DE OUTONO INVERNO, NA REGIÃO SUL DE MINAS GERAIS' ${ }^{1}$
}

\author{
ANA CAROLINA FAVERO ${ }^{2}$, DANIELANGELUCCI DE AMORIM ${ }^{3}$, RENATA VIEIRADAMOTA $^{4}$, \\ ÂNGELA MARIA SOARES ${ }^{5}$, MURILLO DEALBUQUERQUE REGINA ${ }^{6}$
}

RESUMO- O desempenho agronômico da videira ‘Syrah' cultivada em ciclo outono-inverno foi avaliado nos anos de 2005 e 2006, em vinhedo não-irrigado, localizado em Três Corações- MG. Avaliou-se a duração do ciclo entre a poda e a colheita, porcentagem de brotação e fertilidade das gemas, produção, incidência de podridões, superfície foliar primária, potencial hídrico foliar de base, taxa fotossintética líquida, temperatura próxima aos cachos, sólidos solúveis totais, acidez total e $\mathrm{pH}$, durante o período da maturação. Com base nos resultados obtidos, conclui-se que, para as condições climáticas da região cafeeira do sul de Minas Gerais, é possível a alteração do ciclo da videira 'Syrah' em vinhedo não-irrigado, mantendo-se índices de produtividade entre 6,16 e 7,70t.ha-1. Termos para indexação: poda, ciclo de produção, taxa fotossintética, potencial hídrico, Vitis vinifera L.

\section{VIABILITY PRODUCTION OF THE GRAPEVINE 'SYRAH', DURING THE AUTUMN-WINTER CYCLE, IN THE SOUTH OF MINAS GERAIS}

ABSTRACT- Some agronomic parameters of grapevine 'Syrah' during the autumn-winter cycle were evaluated in 2005 and 2006 crops in a non irrigated vineyard located in Três Corações- MG. The complete cycle, sprouting percentage and fertility of buds, production, rottenness incidence, leaf surface, predawn leaf water potential, carbon assimilation rate, temperature near the bunch, total soluble solids, titratable acidity and $\mathrm{pH}$ were evaluated from veraison to harvest. It was concluded that, for the climatic conditions of the coffee region of south Minas Gerais, the modification of grapevine cycle, in a non irrigated vineyard is possible, remaining indices of productivity between 6,16 e 7,70 t.ha ${ }^{-1}$.

Index terms: pruning, production cycle, photosynthesis rate, water potential, Vitis vinifera L.

\section{INTRODUÇÃO}

A variação macroclimática mundial, juntamente com a interferência humana são responsáveis pela diversidade e pela qualidade dos produtos enológicos, sendo o clima um dos fatores mais importantes para a definição da tipicidade do vinho (Tonietto $\&$ Carbonneau, 1999). Dentre os diversos fatores externos que influenciam no crescimento e no desenvolvimento das plantas, Costacurta \& Roselli (1980) e Hidalgo (1993) afirmam que as exigências climáticas da videira são definidas fundamentalmente pela temperatura, luminosidade, umidade atmosférica e disponibilidade hídrica.

A vitivinicultura nacional tem evoluído para a melhoria da qualidade dos vinhos finos. Entretanto, um dos grandes entraves à evolução está na melhoria da qualidade da matériaprima (Regina et al., 2006). Com exceção do Nordeste brasileiro, as principais regiões produtoras de vinhos do País geralmente possuem apenas um ciclo de produção, onde, na maioria dos casos, o momento da maturação e colheita coincide com os meses de maior precipitação pluviométrica. Dessa forma, a elevada incidência de doenças fúngicas, aliada à baixa radiação solar, ao excesso de água no solo e a outros fatores climáticos impedem que a uva atinja a completa maturação, comprometendo a qualidade dos vinhos (Regina et al., 2006). Por outro lado, nas regiões tropicais, as temperaturas elevadas, junto com a baixa amplitude térmica, dificultam a concentração dos compostos fenólicos essenciais para dar cor, estrutura e estabilização aos vinhos (Kliewer, 1970; Bergqvist et al., 2001; Spayd et al., 2002; Mori et al., 2004; Amorim et al., 2005).

Em Minas Gerais, a viticultura voltada à elaboração de vinhos concentra-se na região sul do Estado, principalmente nos municípios de Caldas e Andradas. Nesses locais, assim como na maioria das regiões vitícolas do País, o período da colheita também ocorre nos meses de janeiro e fevereiro, momento de maior precipitação pluviométrica. Entretanto, estudos preliminares realizados no município de Três Corações, região cafeeira do sul de Minas Gerais, mostraram que a cultivar Syrah apresentou boa adaptação quando o ciclo foi transferido para os meses de janeiro a julho, permitindo a colheita no período seco (Amorim et al., 2005).

O presente trabalho objetivou avaliar alguns aspectos agronômicos, juntamente com algumas respostas fisiológicas, de videiras, cv. Syrah, conduzidas em ciclo de outono-inverno, entre janeiro e julho, onde o foco das avaliações centrou-se nas

${ }^{1}$ (Trabalho 220-07). Recebido em: 25-09-2007. Aceito para publicação em: 10-04-2008.

${ }^{2}$ Eng. Agr. MsC., Doutoranda DAG/UFLA. Caixa Postal 3037, CEP 37200-000 Lavras-MG. E-mail: acfavero@yahoo.com.br

${ }^{3}$ Eng. Agr. MsC., EPAMIG. Caixa Postal. 33, CEP 37780-000 Caldas-MG. E-mail: daniel@epamigcaldas.gov.br

${ }^{4}$ Eng. Agr. DsC., EPAMIG - Caixa Postal, 33, CEP 37780-000 Caldas-MG. E-mail: renata@epamigcaldas.gov.br,

${ }_{5}^{5}$ ísica PhD. Universidade Federal de Lavras, Departamento de Biologia, Setor Fisiologia Vegetal, Caixa Postal, 3037, CEP 37200-000 Lavras-MG.

E-mail: amsoares@ufla.br

${ }^{6}$ Eng. Agr. PhD. EPAMIG. Caixa Postal, 33, CEP 37780-000 Caldas-MG. E-mail: murillo@epamigcaldas.gov.br 
indagações sobre a viabilidade da produção extemporânea em vinhedo não-irrigado.

\section{MATERIAL E MÉTODOS}

Este trabalho foi realizado durante os anos de 2005 e 2006, em propriedade privada denominada Fazenda da Fé, localizada em Três Corações, sul de Minas Gerais, a 900 metros de altitude, nas coordenadas $21^{\circ} \mathrm{S}$ e $45^{\circ} \mathrm{O}$.

A área experimental foi composta por 300 plantas, com espaçamento de $2,5 \mathrm{~m} \times 1,5 \mathrm{~m}$, em vinhedo não-irrigado, implantado em agosto de 2001, em terreno de encosta não sujeito à geada, e com mudas da cultivar Syrah, clone 747 do "Etablissement National Technique pour l'Amélioration de la Viticulture - Institut National de la Recherche Agronomique" (ENTAV - INRA ${ }^{\circledR}$ ), enxertadas sobre o porta-enxerto 3309 C. As plantas foram conduzidas em duplo cordão esporonado, no suporte espaldeira. O sistema de poda adotado foi de dupla poda, que consistiu numa primeira poda de formação de ramos realizada em agosto, onde a produção foi eliminada quando os cachos estavam no estádio pré-florada, e uma segunda poda, de produção, realizada em janeiro, quando os sarmentos já estavam lignificados (porém enfolhados), conforme descrição de Amorim et al. (2005) e Regina et al. (2006). Tanto na poda de formação como na de produção, adotou-se o sistema de poda curta (esporão com duas gemas) e aplicou-se cianamida hidrogenada (Dormex ${ }^{\circledR}$ ) por pincelamento direto das gemas, na dosagem de $6,0 \%$ do produto comercial.

$\mathrm{Na}$ área experimental, foram escolhidas, ao acaso, 24 plantas, nas quais se avaliaram as seguintes características: duração do ciclo e fenologia, porcentagem de brotação, índice de fertilidade das gemas, produção, incidência de podridões, superfície foliar primária, potencial hídrico foliar de base $\left(\Psi_{\text {base }}\right)$, taxa fotossintética líquida, temperatura próxima ao cacho, teor de sólidos solúveis totais, acidez total e $\mathrm{pH}$ durante o período da maturação dos frutos.

Os registros fenológicos foram obtidos adotando-se critérios definidos por Carbonneau (1981).

Para a avaliação da porcentagem de brotação, realizaramse a contagem de gemas deixadas na poda e o número de brotações desenvolvidas.

O índice de fertilidade das gemas foi obtido dividindo-se o número de cachos produzidos pelo número de ramos de cada planta.

A produção foi avaliada por contagem e pesagem dos cachos por planta.

O índice de ataque de podridões (podridão da uva madura e podridão ácida) foi avaliado por meio de uma escala de notas de 1 (ausência de sintomas) a 9 (ataque muito forte, acima de $50 \%$ ), de acordo com a severidade das doenças, proposta pela Embrapa Uva e Vinho (EMBRAPA/CNPUV, s.d.). A avaliação foi realizada em 100 cachos, obtidos no momento da colheita.

Durante o estádio fenológico de maturação, após o desponte de ramos, foram feitas avaliações da superfície foliar primária, que representa apenas os ramos principais, através da metodologia proposta por Carbonneau (1976).

O potencial hídrico foliar de base foi acompanhado durante o período do fechamento dos cachos até próximo à colheita, utilizando-se de uma câmara de pressão tipo Scholander (Soilmoisture Equipment Corp., modelo 3005), com as medidas realizadas entre 04h30 e 05h30 da manhã. Foram amostradas 13 folhas adultas e sem danos físicos, coletadas na porção mediana de ramos produtivos de diferentes plantas.

A taxa de assimilação fotossintética das folhas foi avaliada no mesmo dia do potencial hídrico foliar, com o auxílio de analisador portátil de $\mathrm{CO}_{2}$ por infravermelho (IRGA), modelo CID 301 PS, trabalhando em circuito aberto. As medições foram feitas entre $09 \mathrm{~h}$ e $11 \mathrm{~h}$, em condição de luminosidade acima de 900 $\mu \mathrm{mol} \cdot \mathrm{m}^{-2} \cdot \mathrm{s}^{-1}$. Para essa avaliação, foram selecionadas 10 folhas adultas, sadias, completamente expostas à radiação solar e situadas na porção mediana de ramos produtivos de diferentes plantas.

A temperatura próxima ao cacho foi acompanhada durante toda a maturação até a colheita, através de um sensor de temperatura (MultLog, modelo DT 013), com intervalo de temperatura de $-25^{\circ}$ até $110^{\circ} \mathrm{C}$. Os dados foram coletados a cada 30 minutos, durante todo o período, e armazenados em data logger (MultLog, modelo DB-526 VER-5).

As análises do teor de sólidos solúveis totais (SST), acidez total tilulável e $\mathrm{pH}$ foram feitas utilizando-se de mostos provenientes de 200 bagas, colhidas nas 24 plantas (repetições). O teor de SST foi determinado com o auxílio de refratômetro manual (marca ATAGO, escala de 0 a $28^{\circ}$ Brix) e o resultado expresso em ${ }^{\circ}$ Brix. A acidez total foi determinada por titulação com $\mathrm{NaOH} 0,1 \mathrm{~N}$, utilizando indicador fenolftaleína $1 \%$ e o resultado expresso em meq. $\mathrm{L}^{-1}$. $\mathrm{O} \mathrm{pH}$ do mosto foi obtido com pHmetro de bancada (mod. B 474 Micronal), calibrado com padrões $\mathrm{pH} 4,0$ e $\mathrm{pH} 7,0$.

\section{RESULTADOS E DISCUSSÃO}

Verificou-se que a duração do ciclo foi de 195 dias e 180 dias, com um período de maturação de 94 e 86 dias para os anos de 2005 e 2006, respectivamente (Tabela 1).

Souza et al. (2002) verificaram, para a cultivar Syrah, cultivada em ciclo de verão no município de Caldas-MG, um período de 154 dias, ou seja, em torno de 33 dias a menos do que o verificado neste trabalho.

Por outro lado, os resultados verificados neste trabalho estão próximos dos 193 dias, verificados por Ginestar et al. (1998) para o ciclo da videira 'Syrah' cultivada na Austrália, durante o verão.

O aumento da duração do ciclo nas safras de inverno é explicado pelas temperaturas ambientais mais baixas e pode ser traduzido como uma vantagem em relação ao ciclo de verão, já que a permanência dos cachos na planta por um período maior, durante a maturação, pode proporcionar benefícios nas características químicas dos frutos (Rosier, 2006).

A porcentagem de brotação apresentou valores de 68,78 e $65,12 \%$, para 2005 e 2006 , respectivamente (Tabela 2). Os resultados foram superiores aos $48 \%$ encontrados por Amorim et al. (2005), para a 'Syrah', em experimento realizado no mesmo local, durante o ciclo de inverno. O índice de fertilidade das gemas 
foi de 1,49 e 1,18, refletindo em uma média de 20,75 e 20,25 cachos por planta. Esses valores estão próximos aos observados por Regina \& Audeguin (2005), de 19,1 e 20,0 cachos por planta, para os clones 100 e 174 dessa mesma cultivar, na região sul da França.

Por ocasião da colheita, as massas médias dos cachos foram de $111,15 \mathrm{~g}$ e $142,56 \mathrm{~g}$, levando a uma produção por planta de 2,31 e 2,89kg, respectivamente, para as safras de 2005 e 2006 (Tabela 2). Por meio desses valores, estimou-se a produtividade por hectare, que foi de 6,16 t.ha ${ }^{-1}$ para 2005 e 7,70 t.ha- ${ }^{-1}$ para 2006, considerando-se a densidade de 2.666 plantas.ha $^{-1}$. A maior produtividade para o ano de 2006 foi verificada pelo aumento da massa dos cachos, que pode ter sido influenciado devido ao maior acúmulo de reservas na planta em função da idade mais avançada.

Esses valores foram inferiores aos encontrados para a 'Syrah', em ciclo de verão, por Souza et al. (2002), em que a produtividade estimada foi de 10,9 t.ha- ${ }^{-1}$. A superioridade dos valores verificados para o ciclo de verão pode ser associada ao maior índice pluviométrico encontrado nessa estação, o qual promove maior crescimento da baga (alargamento celular), aumentando seu volume e, conseqüentemente, elevando a massa das bagas e dos cachos. Por outro lado, as produções por planta foram comparáveis àquelas observadas por Regina \& Audeguin (2005), na França, com 2,4 kg.planta ${ }^{-1}$ para o clone 174 e 1,48 kg.planta ${ }^{-1}$ para o clone 470.

Para os dois anos estudados, não foi observada qualquer incidência de podridões. Na Figura 1, observa-se que, para a região de Três Corações, o maior índice pluviométrico ocorre nos meses de outubro a março, e os menores índices ocorrem de abril a setembro, indicando que, no período da colheita da safra de outono-inverno, as condições climáticas são desfavoráveis à incidência e disseminação de podridões, permitindo a maior permanência dos frutos na planta e, conseqüentemente, favorecendo a maturação das bagas, observações que concordam com as afirmações de Sentelhas (1998) e Tonietto \& Mandelli (2003)

Os valores da superfície foliar primária foram de $3,11 \pm$ $0,28 \mathrm{~m}^{2}$ e $3,78 \pm 0,68 \mathrm{~m}^{2}$, para os anos de 2005 e 2006, respectivamente. Para o mesmo sistema de condução, Kliewer \& Dokoozlian (2005) afirmaram que, para se obter o nível máximo de sólidos solúveis totais, peso da baga e coloração no momento da colheita, a área foliar $\left(\mathrm{m}^{2}\right)$ por quilograma de fruto, para as cultivares Thompson Seedless, Tokay, Chenin Blanc e Cabernet Sauvignon, deve ser entre 0,5 a $0,8 \mathrm{~m}^{2}$. Observando-se a produção média por planta (Tabela 2) e multiplicando-se esse valor ao valor mínimo observado pelos autores, nota-se que os dados de superfície foliar verificados neste experimento apresentam valores superiores aos indicados. Além disso, os resultados estão próximos à faixa entre 1 e $2 \mathrm{~m}^{2}$ indicados por Toda (1991), como superfície foliar adequada para o amadurecimento de $1 \mathrm{~kg}$ de uva.

A evolução do potencial hídrico de base, desde o fechamento dos cachos até próximo à colheita, pode ser observada na Tabela 3. Os valores inferiores a $-0,1$ observados no ciclo de inverno, nas safras de 2005 e 2006 em Três Corações (Tabela 3), indicam ausência de déficit hídrico, conforme indicações de Carbonneau (1998) e Deloire et al. (2004).
Os resultados das taxas fotossintéticas (Figura 2) estão de acordo com os valores encontrados por Regina \& Aldeguin (2005), que verificaram variações entre 8 e $12 \mu \mathrm{mol} \mathrm{CO} \cdot \mathrm{m}^{-2} \cdot \mathrm{s}^{-1}$ para diferentes clones de 'Syrah' cultivados na região mediterrânea da França. Esses índices, associados aos valores observados para o potencial hídrico foliar de base, permitem afirmar que, para as condições deste estudo, o segundo ciclo da videira pode ser completado apenas com a reserva hídrica do solo, não havendo necessidade de reposição de água por irrigação.

O acompanhamento da temperatura próxima aos cachos durante o período de maturação (Figura 3) mostrou que as máximas variaram entre $16,4 \mathrm{e} 29,5^{\circ} \mathrm{C}$, em 2005 , e $21,0 \mathrm{e} 29,0^{\circ} \mathrm{C}$, em 2006. De acordo com Toda (1991), temperaturas elevadas são fundamentais para a degradação do ácido málico. Esse ácido é o principal substrato da combustão respiratória e o que contribui, em maior proporção, para a diminuição da acidez da baga. Sob condições de baixas temperaturas ambientais, a respiração é desacelerada, com conseqüente diminuição da sua degradação e atraso na maturação dos frutos.

Com relação às temperaturas mínimas, em 2005, as médias oscilaram entre 3,9 e $15,6^{\circ} \mathrm{C}$ e, para o ano de 2006 , entre 1,9 e $13,9^{\circ} \mathrm{C}$. Apesar de esses valores estarem próximos às temperaturas favoráveis às geadas, Tonietto et al. (2006) afirmaram que a probabilidade de ocorrência desse fenômeno na região é de $20 \%$, ou seja, uma geada a cada cinco anos. Ao mesmo tempo, nesta condição de cultivo, a localização ideal dos vinhedos seriam as encostas, devido a drenagem do solo e melhor exposição ao sol, coincidindo também com as parcelas mais elevadas e com menor risco de geada, já que, quando essas ocorrem, limitam-se às baixadas.

As amplitudes térmicas observadas durante o período foram de $14,8^{\circ} \mathrm{Ce} 17,3^{\circ} \mathrm{C}$ para 2005 e 2006 , respectivamente. Mori et al. (2005) observaram que, quando a amplitude térmica na região dos cachos foi de $15^{\circ} \mathrm{C}$, houve um aumento na concentração de antocianinas das bagas.

A evolução do teor de sólidos solúveis totais foi semelhante para os dois anos, com exceção do último ponto da curva de maturação para o ano de 2005, onde foi verificada uma redução inesperada nesses teores (Figura 4). Essa redução pode ser explicada pela diluição dos sólidos solúveis totais, ocasionada pelas chuvas que, excepcionalmente, ocorreram no mês de julho, período que antecedeu a colheita (Figura 1). No momento da colheita, o valor para o ano de 2005 foi $18,84^{\circ}$ Brix e $21,48^{\circ}$ Brix para 2006 (Tabela 4). Essas médias ficaram abaixo dos $23^{\circ}$ Brix relatados para a 'Syrah' por Ginestar et al. (1998), na Austrália. Entretanto, elas podem ser consideradas adequadas, quando comparadas com o valor médio de $16,5^{\circ} \mathrm{Brix}$, observado durante 4 safras de verão por Souza et al. (2002), para a mesma cultivar, em ciclo de verão, no sul de Minas Gerais, e, ainda, aos valores entre 19,4 e $19,8^{\circ}$ Brix observados para a 'Cabernet Sauvignon', também em ciclo de verão, no Rio Grande do Sul (Mandelli et al., 2006).

Os valores de acidez total mantiveram-se próximos, a partir da terceira semana de maturação, nos dois anos estudados (Figura 4). Na colheita, os valores foram de 87,72 meq.L. $\mathrm{L}^{-1} \mathrm{e}$ 
97,52meq.L L $^{-1}$, para 2005 e 2006, respectivamente. Esses valores podem ser considerados satisfatórios se comparados aos valores médios de 125 meq.L.- verificados por Souza et al. (2002) para a mesma cultivar, em quatro safras de verão, na região sul de Minas Gerais.

Os valores médios de $\mathrm{pH}$ do mosto no momento da colheita apresentaram valores de 3,55 e 3,32 para os anos de 2005 e 2006, respectivamente. Conforme Champagnol (1986), o pH do mosto depende do tipo e da concentração dos ácidos orgânicos e da concentração de cátions, principalmente, o potássio. Dessa forma, a superioridade do valor de $\mathrm{pH}$ no ano de 2005 pode ter ocorrido pela maior absorção de minerais (cátions) favorecida pela maior precipitação pluviométrica ocorrida em 2005 (Figura $1)$.

Os índices de produtividade e qualidade de frutos obtidos em duas safras e expressos no presente trabalho permitem afirmar que a alteração do ciclo de produção da videira 'Syrah', para um ciclo de outono-inverno em vinhedo não-irrigado, é viável para a região em estudo. As vantagens dessa alteração do ciclo resumem-se, principalmente, na possibilidade de se obterem uvas com teores de maturação e sanidade bastante superiores àqueles obtidos em uvas da mesma cultivar em ciclo de verão, contribuindo positivamente para a melhoria da qualidade do vinho.

TABELA 1 Estádios fenológicos da videira 'Syrah', em ciclo de outono-inverno, dos anos de 2005 e 2006, no município de Três Corações-MG, 2007.

\begin{tabular}{lcccc}
\hline \multirow{2}{*}{ Estádio fenológico } & \multicolumn{2}{c}{2005} & \multicolumn{2}{c}{2006} \\
\cline { 2 - 5 } & Data & D.A.P. ${ }^{*}$ & Data & D.A.P.* \\
\hline Brotação & $01-02-05$ & 13 & $30-01-06$ & 12 \\
Floração & $10-03-05$ & 50 & $01-03-06$ & 42 \\
Ińíc da mudança de cor das bagas & $30-04-05$ & 101 & $22-04-06$ & 94 \\
Final da mudança de cor das bagas & $12-05-05$ & 113 & $07-05-06$ & 109 \\
Colheita & $02-08-05$ & 195 & $17-07-06$ & 180 \\
\hline
\end{tabular}

* D.A.P. $=$ dias após a poda

TABELA 2 - Porcentagem de brotação, índice de fertilidade, número de cachos por planta, massa média dos cachos $(\mathrm{g})$, produção média $(\mathrm{kg})$ por planta e produtividade média estimada (ha) da videira 'Syrah', em ciclo de outono-inverno, nos anos de 2005 e 2006, no município de Três Corações-MG, 2007.

\begin{tabular}{lcc}
\hline \multicolumn{1}{c}{ Característica avaliada } & 2005 & 2006 \\
\hline \% Brotação & $68,78 \pm 12,9$ & $65,12 \pm 12,17$ \\
Índice de fertilidade & $1,49 \pm 0,32$ & $1,18 \pm 0,31$ \\
Número médio de cachos.planta ${ }^{-1}$ & $20,75 \pm 6,08$ & $20,25 \pm 6,02$ \\
Massa média dos cachos (g) & $111,15 \pm 11,29$ & $142,56 \pm 3,14$ \\
Produção média $\left(\mathrm{kggpp}^{-1}\right)$ & $2,31 \pm 0,23$ & $2,89 \pm 0,06$ \\
Produtividade estimada $\left(\mathrm{kggha}^{-1}{ }^{-1}\right)$ & $6.158,46$ & $7.704,74$ \\
\hline
\end{tabular}

TABELA 3- Potencial hídrico foliar de base $\left(\psi_{\text {base }}\right)$, verificado durante os estádios fenológicos de fechamento, pintor, maturação e pré-colheita da videira 'Syrah', em ciclo de outono-inverno, nos anos de 2005 e 2006, no município de Três Corações- MG, 2007.

\begin{tabular}{|c|c|c|}
\hline & 2005 & 2006 \\
\hline Estádio Fenológico & \multicolumn{2}{|c|}{ Fbase (MPa) } \\
\hline Fechamento dos cachos & $-0,05 \pm 0,02$ & $0,00 \pm 0,00$ \\
\hline Final da mudança de cor das bagas & $-0,06 \pm 0,02$ & $0,00 \pm 0,00$ \\
\hline Maturação & $-0,01 \pm 0,02$ & $-0,08 \pm 0,09$ \\
\hline Pré-colheita & $-0,02 \pm 0,02$ & $-0,06 \pm 0,05$ \\
\hline
\end{tabular}

TABELA 4 - Sólidos solúveis totais ( ${ }^{\circ}$ Brix), acidez total titulável (meq. $\mathrm{L}^{-1}$ ) e $\mathrm{pH}$ de frutos da videira 'Syrah', em ciclo de inverno, nas safras de 2005 e 2006, no município de Três Corações-MG. UFLA, LavrasMG, 2007.

\begin{tabular}{lcc}
\hline \multicolumn{1}{c}{ Característica avaliada } & $\mathbf{2 0 0 5}$ & $\mathbf{2 0 0 6}$ \\
\hline Sólidos solúveis totais $\left({ }^{(}\right.$Brix $)$ & 18,84 & 21,48 \\
Acidez total $\left(\right.$ meq. $\left.\mathbf{L}^{-1}\right)$ & 87,72 & 97,52 \\
$\mathrm{pH}$ & 3,55 & 3,32 \\
\hline
\end{tabular}

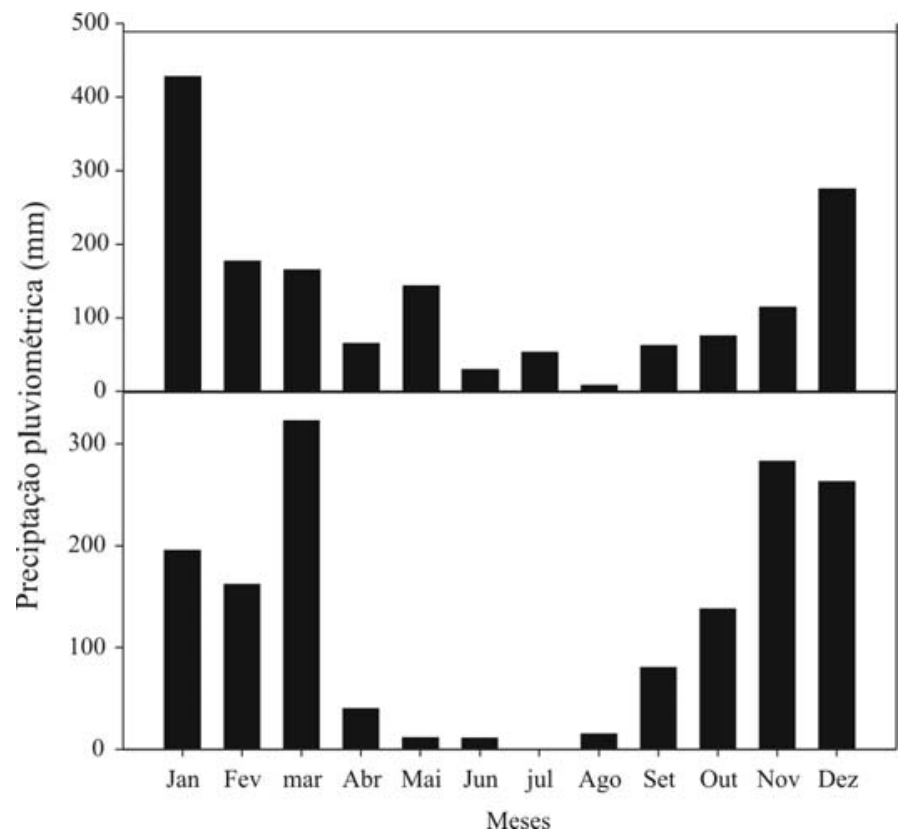

FIGURA 1 - Precipitação pluviométrica total mensal durante os anos de 2005 e 2006, no município de Três Corações-MG, 2007. 


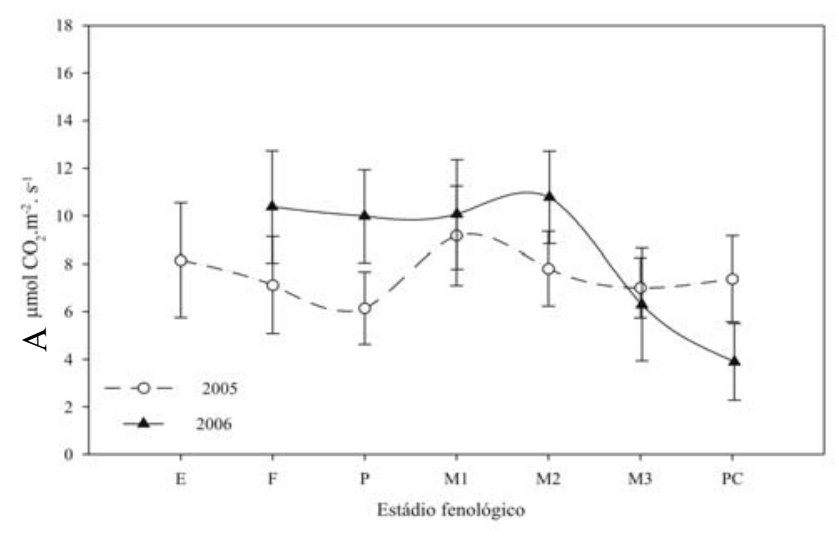

E - enchimento do cacho; F - fechamento do cacho; P - Pintor; M - maturação, e PC - pré-colheita

FIGURA 2 -Taxa fotossintética líquida (A) da videira 'Syrah', em ciclo de outono-inverno, nos anos de 2005 e 2006, no município de Três Corações-MG, 2007.

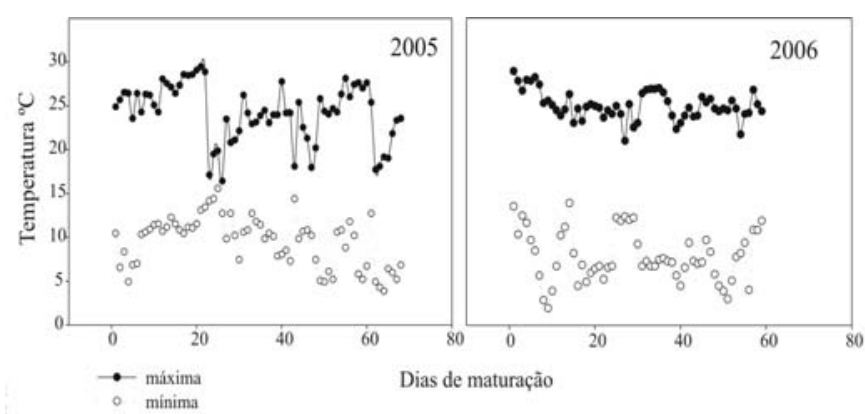

FIGURA 3 -Temperaturas máximas e mínimas da região do cacho, durante o período de maturação da videira 'Syrah', em ciclo de outono-inverno, nos anos de 2005 e 2006, no município de Três Corações-MG, 2007.

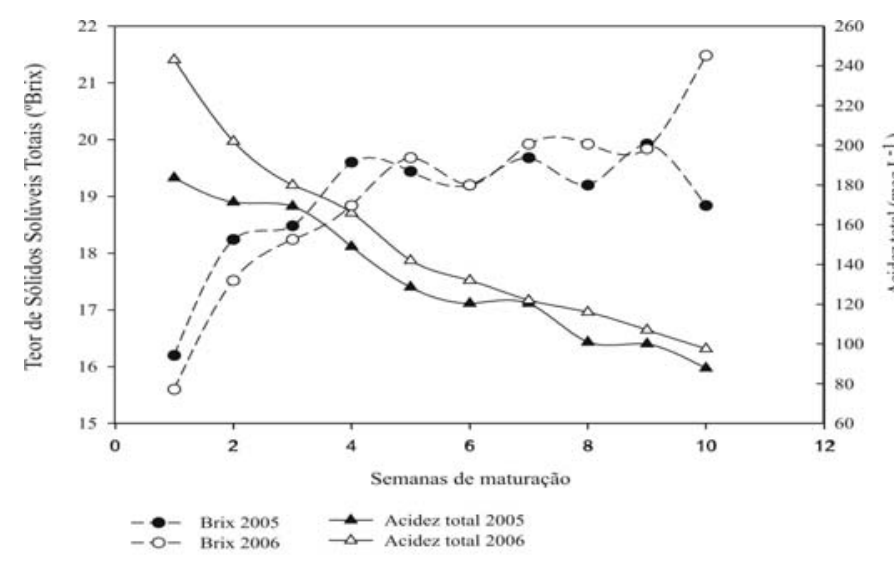

FIGURA 4 - Teor de sólidos solúveis totais ( ${ }^{\circ}$ Brix) e acidez total (meq.L -1 $^{-1}$, durante o período de maturação da videira 'Syrah', em ciclo de outono-inverno, nos anos de 2005 e 2006, no município de Três Corações-MG, 2007.

\section{CONCLUSÕES}

1-Em vinhedo não-irrigado, a videira 'Syrah' responde à dupla poda, exprimindo, no ciclo de inverno, índices de desenvolvimento, produção e qualidade suficientes para viabilizar a cultura na região.

2-O período compreendido entre poda e colheita é de aproximadamente 187 dias.

3- A baixa precipitação e a amplitude térmica característica do período de colheita do inverno favoreceram a qualidade da uva.

\section{AGRADECIMENTO}

À CAPES, pela concessão de bolsa de mestrado à primeira autora; à FAPEMIG e CNPq, pelo financiamento do projeto; à Fazenda da Fé e à empresa Vitácea Brasil, pela colaboração prestada ao desenvolvimento do trabalho.

\section{REFERÊNCIAS}

AMORIM, D. A.; FAVERO, A. C.; REGINA, M. A. Produção extemporânea da videira, cv. Syrah, nas condições do sul de Minas Gerais. Revista Brasileira de Fruticultura, Jaboticabal, v. 27, n. 2, p. 327-331, ago. 2005.

BERGQVIST, J.; DOKOOZLIAN, N.; EBISUDA, N. Sunlight exposure and temperature effects on berry growth and composition of Cabernet sauvignon and Grenache in the Central San Joaquin Valley of California. American Journal Enology and Viticulture, Davis, v. 52, n. 1, p. 1-7, 2001.

CARBONNEAU, A. Analise de la croissance des feuilles du sarment de vigne : Estimation de la surface foliare par enchantillonnage. Connaissance Vigne Vin, Bordeaux, v. 10, n. 2, p. 141-159, juil. 1976.

CARBONNEAU, A. Aspects qualitatifs. In: TIERCELIN, J.R. (Ed.). Traité d' irrigation. Paris: Lavoisier, 1998. p. 258-276.

CARBONNEAU, A. Observations sur vigne. Codification des données agronomiques. Vitis, Siebeldigen, v. 5, n. 2, p. 9-13, 1981.

CHAMPAGNOL, F. L'acidité des moûts et des vins. Revue Française d'Oenologie, Montpellier, v. 26, n. 104, p. 26-57, 1986.

COSTACURTA, A.; ROSELLI, G. Critères climatiques et édaphiques pour l'établissement des vignobles. Bulletin de I'O.I.V, Paris, v. 53, n. 596, p. 783-786, 1980.

DELOIRE, A.; CARBONNEAU, A.; WANG, Z. P. ; OJEDA, H. Vine and water : a short review. Jounal International Des Scienes 
de la Vigne et Du vin, Bordeaux, v. 38, n. 1, p. 1-13, jan./mars. 2004

EMBRAPA/CNPUV. Descritores mínimos para avaliação de cultivares de videiras. Bento Gonçalves, [s.d.]. Documento de circulação restrita.

GINESTAR, C.; EASTHAM, J.; GRAY, S.; ILAND, P. Use of sapflow sensors to schedule vineyard irrigation. II. Effects of postverasion water deficits on composition of shiraz grapes. American Jounal Enology and Viticulture, Davis, v. 49, n. 4, p. 421-428, 1998

HIDALGO, L. Tratado de viticultura. Madrid: Ediciones MundiPrensa, 1993.

KLIEWER, W. M. Effect of day temperature and light intensity on coloration of Vitis vinifera L. Grapes. Journal of the America Society Horticultural Science, Alexandria, v. 95, n. 6, p. 693-697, 1970.

KLIEWER, W. M.; DOKOOZLIAN, N. K. Leaf area/crop weight ratios of grapevines: influence on fruit composition and wine quality. American Journal Enology and Viticulture, Davis, v. 56, n. 2, p. 170-181, 2005.

MANDELLI, F.; MIELE, A.; RIZZON, L. A. Influência do tipo de poda na produtividade e composição do mosto da uva Cabernet sauvignon em dois sistemas de condução. In: CONGRESSO BRASILEIRO DE FRUTICULTURA: Frutas do Brasil, saúde para o mundo, 19., 2006, Cabo Frio. Resumos... Cabo Frio: SBF/UENF/ UFRRJ, 2006. p. 228.

MORI, K.; SAITO, H.;GOT-YAMAMOTO, N.;KITAYAMA, M.; KOBAYASHI, S.; SUGAYA, S.; GEMMA, H.; HASHIZUME, K. Effects of abscisic acid treatment and night temperatures on anthocyanin composition in Pinot noir grapes. Vitis, Siebeldingen, v. 44, n. 4, p. 161-165, 2005.

MORI, K.; SUGAYA, S.; GEMMA, H. Regulatory mechanism of anthocyanin biosynthesis in 'Kyoto' grape berries grown under different temperatures conditions. Environmental Control in Biology, Tokyo, v. 42, p. 21-30, 2004.
REGINA, M. A.; AMORIM, D. A.; FAVERO, A. C.; MOTA, R. V.; RODRIGUES, D. J. Novos pólos vitícolas para produção de vinhos finos em Minas Gerais. Informe Agropecuário, Belo Horizonte, v. 27, n. 234, p. 111-118, 2006.

REGINA, M. A.; AUDEGUIN, L. Avaliação ecofisiológica de clones de videira cv. Syrah. Ciência e Agrotecnologia, Lavras, v. 29, n. 4, p. 875-879, 2005.

ROSIER, J. P. Vinhos de altitude: característica e potencial na produção de vinhos finos brasileiros. Informe Agropecuário, Belo Horizonte, v. 27, n. 234, p. 105-110, 2006.

SENTELHAS, P. C. Aspectos climáticos para a viticultura tropical. Informe Agropecuário, Belo Horizonte, v. 19, n. 194, p. 9-14, 1998.

SOUZA, C. M.; REGINA, M. A.; PEREIRA, G. E. FREITAS, G. F.; Indicação de cultivares de videira para o sul de Minas Gerais. In: REGINA, M. A. (Coord.). Viticultura e enologia: atualizando conceitos. Caldas: EPAMIG-FECD, 2002.p. 277-286.

SPAYD, S. E.; TARARA, J. M.; MEE, D. L.; FERGUSON, J. C. Separation of sunlight and temperature effects on the composition of Vitis vinifera cv. Merlot berries. American Journal Enology and Viticulture, Davis, v. 53, p. 171-181, 2002.

TODA, F. M. Biologia de la vid: fundamentos biológicos de la viticultura. Madrid: Ed. Mundi-Prensa, 1991. 346 p.

TONIETTO, J. ; CARBONNEAU, A. Análise mundial do clima das regiões vitícolas e de sua influência sobre a tipicidade dos vinhos: a posição da viticultura brasileira comparada a 100 regiões em 30 países. In: CONGRESSO BRASILEIRO DE VITICULTURA E ENOLOGIA, 9., 1999, Bento Gonçalves-RS. Anais... Bento Gonçalves: Embrapa Uva e Vinho, 1999. p. 75-90.

TONIETTO, J.; MANDELLI, F. Uvas Viníferas para processamento em regiões de clima temperado: clima. Brasília: EMBRAPA- SP4, versão eletrônica. julho 2003. Disponível em: $<$ http://www.cnpuv.embrapa.br/publica/sprod/viniferas/ clima.htm> . Acesso em: 09 out. 2006. 